\title{
The effect of radionuclide and heavy metal contamination of the Yenisei River on cytogenetics of aquatic plant Elodea canadensis
}

\author{
A. Bolsunovsky ${ }^{1,2}$, E. Muratova ${ }^{3}$, A. Sukovaty ${ }^{2}$ and M. Kornilova ${ }^{3}$ \\ ${ }^{1}$ Institute of Biophysics Siberian Branch Russian Academy of Sciences, Akademgorodok, \\ 660036 Krasnoyarsk, Russia \\ ${ }^{2}$ Siberian Federal University, 79 Svobodnyi Ave., 660041 Krasnoyarsk, Russia \\ ${ }^{3}$ Institute of Forest Siberian Branch Russian Academy of Sciences, Akademgorodok, \\ 660036 Krasnoyarsk, Russia
}

\begin{abstract}
The study was done to determine concentrations of radionuclides and heavy metals and to evaluate the frequency of chromosomal aberrations in samples of Elodea canadensis, a submerged plant, collected in different parts of the Yenisei River. Samples were collected in the area subjected to radioactive impact of the Mining-and-Chemical Combine (MCC) at Zheleznogorsk and in the control areas, upstream of the MCC. The investigations showed that Elodea biomass in the area affected by MCC operation contained a long inventory of artificial radionuclides typical of the MCC discharges. Upstream of the MCC, in the control sampling areas, the sediments and the Elodea biomass contained only one artificial radionuclide $-{ }^{137} \mathrm{Cs}$. Thus, the exposure doses to Elodea shoots and roots upstream of the MCC are small (not more than $8 \mu \mathrm{Gy} / \mathrm{d}$ ) and the main contribution to them is made by natural radionuclides. At the MCC discharge site (the village of Atamanovo) and downstream of it, the total dose rate increases almost an order of magnitude, reaching its maximal values $-72 \mu \mathrm{Gy} / \mathrm{d}$ for Elodea shoots and $58 \mu \mathrm{Gy} / \mathrm{d}$ for roots. Cytogenetic investigations of Elodea roots showed that at the MCC discharge site (the village of Atamanovo) and downstream of it the occurrence of chromosomal aberrations in ana-telophase and metaphase cells of Elodea was considerably higher than in the control area. It is highly probable that this simultaneous dramatic increase in the total exposure rate and the occurrence of chromosomal aberrations in Elodea is associated with the radiation factor. It is suggested that Elodea is affected not only by the radiation factor but also by the chemical factor - toxicity of heavy metals.
\end{abstract}

\section{INTRODUCTION}

The Yenisei River, one of the world's largest rivers, is contaminated with artificial radionuclides released by one of the Russian facilities producing weapons-grade plutonium (the Mining-and-Chemical Combine), which has been in operation for many years [1, 2]. At the present time, besides longlived radionuclides, the river also receives radionuclides of activation origin with the coolant of the nuclear reactor. Gamma-spectrometric analysis and radiochemical investigations of samples of aquatic organisms revealed a broad spectrum of long-lived and short-lived radionuclides, including transuranium elements [3, 4]. Taking into account high concentration factors of artificial radionuclides for aquatic organisms, calculations were done to estimate internal dose rates for aquatic organisms of the Yenisei River near the MCC [4]. The water moss (Fontinalis antipyretica) featured the highest capacity to accumulate manmade radionuclides; hence, it accumulated the largest artificial exposure dose among the study aquatic organisms $[4,5]$. However, all the earlier investigated samples of aquatic organisms were collected near the MCC discharge site, and just a few species of aquatic plants were subjected to analysis. One of the species that have not been investigated sufficiently is Elodea canadensis, which is abundant in the Yenisei River and which is traditionally used as a bioindicator in monitoring of aquatic ecosystems. As aquatic plants are very good concentrators of radionuclides and heavy metals, one would expect emergence of cytogenetic effects. 
The purpose of the study was to assess levels of radionuclides and heavy metals and to evaluate the frequency of chromosomal aberrations in samples of Elodea canadensis, a submerged plant, collected in different parts of the Yenisei River.

\section{MATERIALS AND METHODS}

Samples of the aquatic plant Elodea canadensis (Canadian waterweed) were collected from the Yenisei River both near the MCC (at the villages of Atamanovo and B. Balchug) and at a distance of $250 \mathrm{~km}$ downstream of the MCC (at the villages of Zakharovka and Strelka) (Fig. 1). Control sampling area No. 1 was located upstream of the MCC, $45 \mathrm{~km}$ downstream of Krasnoyarsk, at the village of Esaulovo. Control sampling area No. 2 was very close to Krasnoyarsk, just slightly upstream (at the village of Udachnyi). Control area No. 1 receives non-radioactive industrial effluents; no industrial effluents are discharged into the Yenisei at control area No. 2. In addition to plants, water and sediment samples were collected at all sampling positions, too.

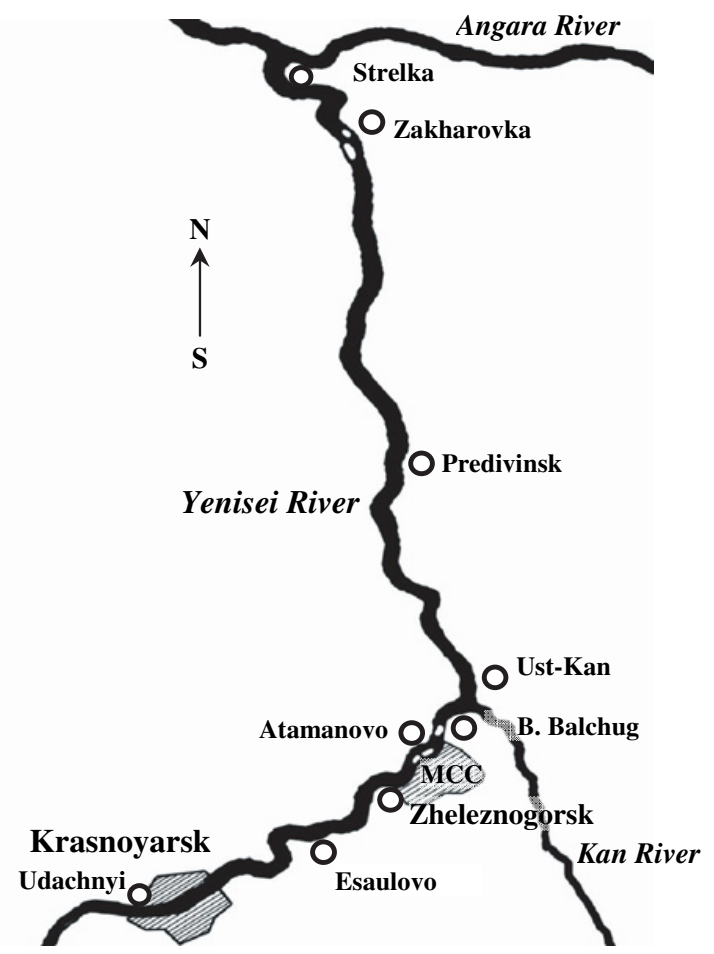

Figure 1. Diagrammatic map of the south of the Krasnoyarsk Territory (Russia), showing settlements near which samples of sediments and acquatic plants were collected. Scale 1:2000 000.

\subsection{Measurements of radionuclides and heavy metals in samples}

The activity concentrations of the $\gamma$-emitting nuclides in the samples were measured on a $\gamma$-spectrometer (Canberra, USA) coupled to a hyper-pure germanium detector. The $\gamma$-spectra were processed using the CANBERRA GENIE 2000 software (USA). Aquatic organisms of the Yenisei River are known to contain not only $\gamma$-emitting nuclides, but also ${ }^{32} \mathrm{P}-$ an incorporated $\beta$-emitting radionuclide of activation origin. Concentration of ${ }^{32} \mathrm{P}$ in some plant samples was calculated from the results of measurements of 
total $\beta$-activity on a UMo LB 123 instrument coupled to an LB 1238 detector (Berthold, Germany) and on a Tri-Carb 2800 TR liquid scintillation spectrometer (PerkinElmer/Packard, USA). The activity concentrations of radionuclides in the dry biomass of aquatic organisms were determined as of the date of sampling. To assess industrial metal contamination of the river, sediments and Elodea biomass were measured to determine major and trace elements. Sediments and Elodea biomass were analyzed in the Analytical Laboratory of the Institute of Biophysics SB RAS, using Carl Zeiss equipment: an emission spectrometer, a FLAPHO-4 flame photometer, and an AAS-IN atomic absorption spectrometer.

\subsection{Calculation of the total exposure dose rate to Elodea}

In the general case, the calculations of the radiation dose rates are rather complicated, so, to simplify them, radionuclides are taken to be uniformly distributed over the organism and in its environment. To calculate exposure dose rates, we used methods and techniques reported elsewhere $[4,5]$. The total exposure dose rates were separately calculated for Elodea roots and shoots (stems with leaves). The total exposure dose rate was made up of the internal exposure dose rate due to incorporated radionuclides and the external exposure. External sources of exposure for Elodea canadensis shoots are radionuclides in the water and sediment and for roots - radionuclides in sediment. The exposure dose rate to aquatic organisms was calculated using the authors' own data on the content of radionuclides in the biomass, water and sediments.

\subsection{Determination of cytogenetic features of Elodea}

Elodea canadensis root meristems were used as study material. The material was treated with a $0.1 \%$ colchicine solution and fixed with acetic alcohol (1:3) in the field. Then the material pretreated with $4 \%$ iron ammonium alum was stained with aceto-hematoxylin. The preparations were examined under an MBI-6 microscope and photographed. Toxicity estimates were based on conventional criteria occurrence and spectrum of chromosomal aberrations in ana-telophase and metaphase cells.

\section{RESULTS AND CONCLUSION}

\subsection{Downstream changes in radionuclide concentrations in biomass of the Yenisei River Elodea and calculation of exposure doses}

In our earlier papers we already wrote $[3,4]$ that the MCC continues releasing the water used as coolant for the nuclear reactor into the Yenisei River. The Yenisei is reported to receive the following radionuclides of activation origin: ${ }^{24} \mathrm{Na},{ }^{32} \mathrm{P},{ }^{46} \mathrm{Sc},{ }^{51} \mathrm{Cr},{ }^{54} \mathrm{Mn},{ }^{58} \mathrm{Co},{ }^{59} \mathrm{Fe},{ }^{64} \mathrm{Cu},{ }^{65} \mathrm{Zn},{ }^{95} \mathrm{Zr}$, ${ }^{95} \mathrm{Nb}$, etc. Table 1 lists the highest concentrations of radionuclides in biomass of Elodea shoots downstream of Krasnoyarsk. Almost all radionuclides typical of MCC effluents have been registered in Elodea plants collected at the MCC discharge site (at the village of Atamanovo) every year. Gamma-spectrometric analysis detected radionuclides of activation origin, such as ${ }^{51} \mathrm{Cr},{ }^{54} \mathrm{Mn},{ }^{58} \mathrm{Co}$, and ${ }^{65} \mathrm{Zn}$, in Elodea shoots collected both near the MCC (the village of Atamanovo) and at a considerable distance $250 \mathrm{~km}$ - downstream (at the villages of Zakharovka and Strelka). Naturally, activity concentrations of radionuclides in the samples of the plants collected downstream of the MCC discharge site were considerably smaller than in the samples collected near the MCC. Earlier, we reported a similar tendency for the aquatic plant Potamogeton lucens (shining weed) [3, 4]. In Elodea shoots we also found the transuranium elements ${ }^{239} \mathrm{~Np}$ and ${ }^{241} \mathrm{Am}$ and the $\beta$-emitters ${ }^{90} \mathrm{Sr}$ and ${ }^{32} \mathrm{P}$. The authors' estimate is that ${ }^{32} \mathrm{P}$ activity concentration can reach $6500 \mathrm{~Bq} / \mathrm{kg}$ in Elodea canadensis biomass. These activities of ${ }^{32} \mathrm{P}$ are almost an order of magnitude higher than the activity of each of the other radionuclides. The radionuclide inventories of Elodea roots and sediments are very similar. Only one artificial 
radionuclide $-{ }^{137} \mathrm{Cs}$ - was detected in aquatic plants collected in control areas 1 and 2, and its activities in shoots and roots did not exceed $5-10 \mathrm{~Bq} / \mathrm{kg}$.

Table 1. Highest radionuclide concentrations (Bq/kg dry mass) in biomass of Elodea canadensis shoots at different distances downstream of Krasnoyarsk.

\begin{tabular}{|l|c|c|c|c|c|}
\hline Radionuclide & $\begin{array}{c}\text { Esaulovo, } \\
\mathbf{4 5} \mathbf{~ k m}\end{array}$ & $\begin{array}{c}\text { Atamanovo, } \\
\mathbf{8 7} \mathbf{~ k m}\end{array}$ & $\begin{array}{c}\text { B. Balchug, } \\
\mathbf{9 7} \mathbf{~ k m}\end{array}$ & $\begin{array}{c}\text { Zakharovka } \\
\mathbf{2 7 8} \mathbf{~ k m}\end{array}$ & $\begin{array}{c}\text { Strelka, } \\
\mathbf{3 3 0} \mathbf{~ k m}\end{array}$ \\
\hline${ }^{7} \mathbf{B e}$ & 70 & 108 & 78 & 78 & 61 \\
\hline${ }^{40} \mathbf{K}$ & 1200 & 1400 & 1200 & 1200 & 1300 \\
\hline${ }^{46} \mathbf{S c}$ & & 39 & 10 & DL & 2 \\
\hline${ }^{51} \mathbf{C r}$ & & 964 & 327 & 116 & 93 \\
\hline${ }^{54} \mathbf{M n}$ & & 84 & 14 & 7 & 7 \\
\hline${ }^{58} \mathbf{C o}$ & & 160 & 48 & 11 & 3 \\
\hline${ }^{60} \mathbf{C o}$ & & 310 & 190 & 45 & 21 \\
\hline${ }^{65} \mathbf{Z n}$ & & 283 & 89 & 13 & 9 \\
\hline${ }^{90} \mathbf{S r}$ & ND & 8 & 5 & ND & ND \\
\hline${ }^{137} \mathbf{C s}$ & 5 & 104 & 46 & 23 & 32 \\
\hline${ }^{152} \mathbf{E u}$ & & 23 & 22 & 11 & 8 \\
\hline${ }^{239} \mathbf{N p}$ & & 100 & 68 & 22 & DL \\
\hline${ }^{241} \mathbf{A m}$ & & 8.5 & 2.4 & 6 & DL \\
\hline${ }^{32} \mathbf{P}$ & & 6500 & 2100 & 700 & 660 \\
\hline
\end{tabular}

$\mathrm{DL}=$ detection limit. $\mathrm{ND}=$ not determined.

As only one artificial radionuclide $\left({ }^{137} \mathrm{Cs}\right)$ and two natural ones $\left({ }^{40} \mathrm{~K}\right.$ and $\left.{ }^{7} \mathrm{Be}\right)$ were registered in Elodea shoots of the control areas, exposure doses received by them were low (not more than $8 \mu \mathrm{Gy} / \mathrm{d}$ ), with the natural radionuclides making the major contribution. At the village of Atamanovo, the total exposure dose rate to Elodea shoots reaches its highest value $-72 \mu \mathrm{Gy} / \mathrm{d}$. The main contribution to the irradiation dose rate is made by ${ }^{32} \mathrm{P}$ (up to $85 \%$ ) and the contribution of the other artificial radionuclides does not exceed $10 \%$. At a considerable distance downstream, at the village of Strelka (330 km north of Krasnoyarsk), the total exposure dose rate drops to $17 \mu \mathrm{Gy} / \mathrm{d}$. Unlike shoots, roots collected at positions between Atamanovo and Strelka receive much higher external exposure doses from radionuclides deposited in sediment than from incorporated radionuclides. At Atamanovo the total exposure rate to Elodea roots reaches its maximum $-58 \mu \mathrm{Gy} / \mathrm{d}$, and at Strelka it decreases to $26 \mu \mathrm{Gy} / \mathrm{d}$. Thus, at Atamanovo (near the MCC) the total exposure dose rate to Elodea shoots and roots is the highest. The downstream decrease in the total exposure dose is greater for Elodea shoots than for Elodea roots.

Comparing these data with the data for a marine ecosystem, one can see that the total dose received by the organisms of the Yenisei River is an order of magnitude larger than the exposure doses to biota of the Arctic and the Pacific seas [6,7]. The marine biota receives most of its exposure dose (up to 99\%) from natural radionuclides. Our estimate of the natural dose rate to aquatic organisms agrees well with the data reported by Vakulovsky and his co-authors [1]. However, our estimate of the artificial dose rate to aquatic plants of the Yenisei River is at least 4 times lower than the dose rate reported in that paper. The reason is quite obvious: the data reported in the cited paper were obtained in 1991, when three reactors were operating at the MCC and the Yenisei received the largest amount of activation radionuclides. At that time, the largest contribution to the artificial dose was made by ${ }^{24} \mathrm{Na},{ }^{32} \mathrm{P}$ and ${ }^{56} \mathrm{Mn}[1]$.

\subsection{Concentrations of metals in Elodea canadensis shoots collected from the Yenisei River at different distances downstream of Krasnoyarsk}

To assess industrial metal contamination of the river, sediments and Elodea biomass were measured to determine major and trace elements. Assuming that industrial and municipal effluents contribute considerably to contamination of the Yenisei River, one would expect that metal levels in sediments 
and submerged plants should decrease downstream of Krasnoyarsk. Measurements of major and trace elements in sediments and Elodea canadensis plants collected from the Yenisei River at different positions between Krasnoyarsk and Strelka (330 km north of Krasnoyarsk) did not reveal any general trends towards increase or decrease in metal levels depending on the position. The distribution of metals is patchy not only downstream but also in the same sampling area. Elodea biomass accumulates larger amounts of $\mathrm{K}, \mathrm{Na}, \mathrm{Ca}, \mathrm{Mn}$ and $\mathrm{Cr}$ than sediments. The only metal that decreases downstream both in sediment and Elodea biomass is Zn. Generally speaking, the initial assumption that levels of most metals in sediments and Elodea biomass should decrease downstream of Krasnoyarsk has not been confirmed.

\subsection{Cytogenetic investigations of Elodea canadensis plants collected from the Yenisei River at different distances downstream of Krasnoyarsk}

Cytogenetic investigations showed that the chromosomes of Elodea collected from the Yenisei River are of small size $(1-2 \mu \mathrm{m})$; morphologically they are two-armed meta- or submetacentric chromosomes. The interphase nuclei of Elodea contain 1-2, seldom 3 or 4, nucleoli. Elodea of the studied part of the Yenisei water area was found to be a mixoploid - the number of chromosomes within one plant varied from 24 to 96 , the most frequently occurring sets containing 24, 32, 40, and 48 chromosomes. The following chromosomal aberrations were observed in ana-telophase cells of Elodea plants from every sampling position: irregular separation and agglutination of chromosomes, expulsion of chromosomes out of the plate, lagging chromosomes, bridges. Cytoplasm vacuolization was revealed in almost $100 \%$ cells of the plants collected near the villages of Strelka and Zakharovka and in 50\% and 30\% cells of the plants collected at Atamanovo and B.Balchug, respectively. In metaphase cells of Elodea plants collected at positions downstream of the MCC, we found circular structures and fragmented chromosomes; cells of the plants collected at Strelka contained micronuclei. In control samples, collected at the village of Esaulovo, we detected just one circular chromosome.

Results of cytogenetic investigations of Elodea roots suggest (Fig. 2) that at the MCC discharge site (the villages of Atamanovo and B.Balchug) and downstream the occurrence of chromosomal aberrations in ana-telophase and metaphase cells of Elodea was considerably higher than in the control areas. In the samples collected in the control areas (near Krasnoyarsk and at the village of Esaulovo), which are

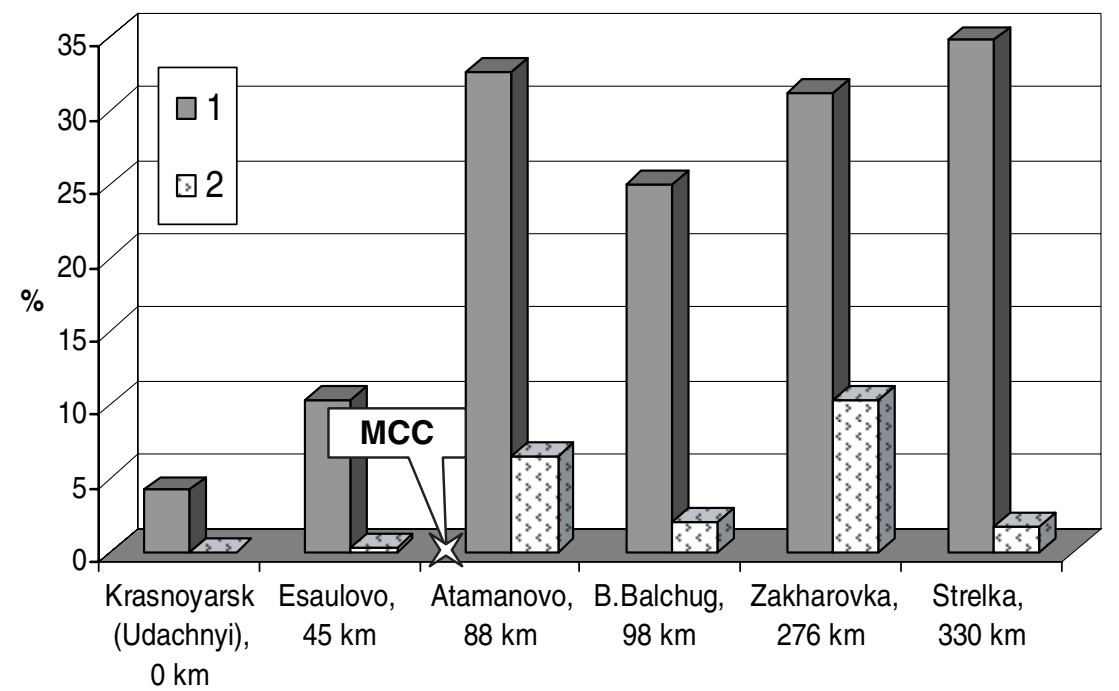

Figure 2. Chromosomal aberrations in ana-telophase (1) and metaphase cells (2) of Elodea canadensis collected from the Yenisei River downstream of Krasnoyarsk. 
not impacted by the radioactive contamination from the MCC, chromosomal aberrations do not exceed 4-10\%, whereas in the samples collected in the area contaminated by the MCC the overall occurrence of chromosomal aberrations in ana-telophase and metaphase cells of Elodea is rather high (up to 35\%). It is highly probable that this simultaneous dramatic increase in the total exposure rate and the occurrence of chromosomal aberrations in Elodea is associated with the radiation factor. However, the maximum exposure dose rates to Elodea that we obtained in our study were much lower than the generally accepted values of exposure dose rates to aquatic biota $-1-10 \mathrm{mGy} / \mathrm{d}-$ that cause radiation effects [8, 9]. It was suggested that Elodea is affected not only by the radiation factor but also by the chemical factor toxicity of heavy metals. Analytical investigations, though, did not reveal metal levels in Elodea that would exceed those reported in the literature. High levels of heavy metals in industrial wastes released into the Yenisei River at Krasnoyarsk on the one hand and rather a low occurrence of chromosomal aberrations in Elodea samples collected near Krasnoyarsk on the other suggest a conclusion about insignificance of the effect of the chemical factor alone. The chemical and radiation factors can exert a concerted (synergic) effect on Elodea plants in the areas of radioactive contamination of the Yenisei River ecosystem.

\section{References}

[1] Vakulovsky, S.M., I.I. Kryshev, A.I. Nikitin, et al., J. Environ. Radioactivity, 29 (1995) 225-236.

[2] Bolsunovsky, A. and L. Bondareva, Journal of Alloys and Compounds, 444-445 (2007) 495-499.

[3] Bolsunovsky, A., Aquatic Ecology, 38 (2004) 57-62.

[4] Bolsunovsky, A., A. Sukovaty and E. Pankov, Radioactive contamination and exposure dose rates of aquatic organisms of the Yenisei River. In: Per Strand, Peer Borretzen and Torun Jolle (Eds.): Environmental Radioactivity in the Arctic \& Antarctic. Norwegian Radiation Protection Authority, Norway, 2005. 138-141.

[5] Sukovaty, A. and A. Bolsunovsky, Exposure dose rates to aquatic organisms of the Yenisei River. In: Per Strand, Torun Jolle and Ase Sand (Eds.): Environmental Radioactivity in the Arctic \& Antarctic. Norwegian Radiation Protection Authority, Norway, 2002. 337- 339.

[6] Brown, J.E. and P. Strand, Modeling doses to biota in environmental system: The $4^{\text {th }}$ Int. Conf. on Environment Radioactivity in the Arctic. Ed. P. Strand. Edinburgh (Scotland), 1999. 125-128.

[7] Danilyan, V.A., V.L. Vysotsky, M.N. Katkova and I.I. Kryshev, Dose rates to aquatic organisms and residents in the vicinity of running the ships equipped with nuclear power plants. Atomnaya energiya (Atomic Energy), 92: 2002. 158-168, in Russian.

[8] A Graded Approach for Evaluating Radiation Doses to Aquatic and Terrestrial Biota (DOE-STD1153-2002, July 2002. USA).

[9] Sazykina T.G., Kryshev I.I. Assessment of the impact of radioactive substances on marine biota of north European waters (Report of Working Subgroup D. Marina II Project. Commission of the European Communities, Report C6496/TR/004 Issue 3 August 2002. 106 p). 